\title{
Psychological Impact of Cutaneous Congenital Vascular Lesions
}

\author{
Katlein França*, Jennifer Ledon BS, Jessica Savas BS and Keyvan Nouri
}

Department of Dermatology and Cutaneous Surgery, University of Miami Miller School of Medicine, Mohs and Laser Clinic, 1475 NW 12 th Avenue, 2175 Miami, FL, USA

\begin{abstract}
Vascular lesions are abnormalities of vascular elements that appear at birth or in infancy. Cutaneous congenital vascular lesions are the most common pediatric birthmarks and can be divided into two different categories: hemangiomas and vascular malformations. Hemangiomas tend to involute, as the child grows older while other vascular malformations tend to persist. Congenital vascular lesions are found most commonly on the head and neck and can be isolated or part of a congenital syndrome such as Klippel-Trenaunay syndrome, Sturge-Weber syndrome and others. Vascular lesions, especially on exposed sites, can cause significant psychological distress for patients and family members.
\end{abstract}

Keywords: Cutaneous vascular lesions; Psychology; Psychodermatology

Cutaneous congenital vascular lesions are the most common pediatric birthmarks. These vascular lesions are abnormalities of blood vessels, both arterial and venous, that appear at birth or in infancy [1]. They are classically divided into hemangiomas and vascular malformations; hemangiomas tend to spontaneously involute while vascular malformations tend to persist $[2,3]$. Congenital lesions are most commonly found on the head and neck and while many are benign isolated findings, some lesions may be part of a congenital syndrome such as Klippel-Trenaunay syndrome, Sturge-Weber syndrome and others [4-6]. Congenital vascular lesions, especially those found in readily visible sites, can lead to psychological distress for both the patient and family members secondary to perceived deformities or disfiguration [7].

Skin is a very complex organ with several biological functions such as sensation, barrier protection, immune surveillance, and thermoregulation. It also plays a role in communication, socialization and human interaction. Dermatological disorders can impair tactile communication, sexual relations and physical interactions $[8,9]$.

The psychological impact of skin disorders has become the focus of study of many physicians worldwide. Increasing the understanding of the psychological impact that skin diseases can cause as well a biopsychosocial approach to managing these cases will ultimately benefit patients and improve their quality of life $[9,10]$.

Current treatment modalities available to treat these cutaneous lesions are topical or intralesional steroids, surgical resection, laser therapy, endovascular therapy, or oral medications, among others [11].

While the current literature mostly addresses medical treatments available and research primarily focuses on the development of new treatments, few studies approach the psychological aspects of these patients. One study, published in the British Journal of Dermatology evaluated the changes in the psychological distress of patients with vascular lesions following laser treatments. The authors used scores on a standard questionnaire before treatment and at 6-month followup. Forty-two patients were enrolled in the study and they had one of four diagnoses: telangiectasia, port wine stains (PWS), vascular spider veins or cherry angioma, which occurred mainly on facial or exposed sites. These patients were treated every $4-8$ weeks with an appropriate laser by the same dermatologist until discharge. The results showed a significant decrease in subjective scores of patients with telangiectasia and vascular spiders yet not PWS or cherry angiomas. Psychological distress had reduced significantly in patients with less severe vascular lesions; however, while patients with PWS showed objective aesthetic improvement, this was not reflected in their subjective (depression/ anxiety) scores [12].

This may suggest that the psychological damage of having a disfiguring mark for a long period of time cannot be immediately reversed with treatment of the lesions. Multidisciplinary approaches may be necessary in these patients.

Children presenting with disfigurements are subject to a wide array of psychological sequelae, including problems with social integration and confidence, negative effects on their self-concept, behavioral problems and late, in adolescence, sexual problems [13-16].

Laser treatment is considered an effective option for the treatment of several cutaneous vascular lesions. Advances in this therapy have allowed for the safe treatment of children with port-wine stains. McDaniel suggests treating these children before they sustain serious psychological damage [17].

Intuitively, children presenting with visible cutaneous vascular lesions may be subject emotional angst and psychological distress. The psychological impact of port wine stains in children and adults was studied by a few authors and contrary to the anticipated results; the negative psychological effects of these types of lesions were not as severe as what had been previously expected.

An interesting study performed by Sheerin et al. [18] investigated and compared the psychological adjustment in children presenting with port-wine stains (PWS) and children with prominent ears (PE). The authors evaluated 32 children aged 7 to 16 years with facial PWS and 42 children using the Harter Self-Perception Profile, the Revised Children's Manifest Anxiety Scale, the Children's Depression Inventory, the Disfigurement Perception Scale, and the Child Behavior Checklist.

*Corresponding author: Katlein França, Department of Dermatology and Cutaneous Surgery, University of Miami Miller School of Medicine, Mohs and Laser Clinic, 1475 NW 12th Avenue, 2175 Miami, FL, USA, E-mail: k.franca@med.miami.edu

Received March 25, 2013; Accepted May 23, 2013; Published May 25, 2013

Citation: França K, Jennifer Ledon BS, Jessica Savas BS, Nouri K (2013) Psychological Impact of Cutaneous Congenital Vascular Lesions. J Vasc Med Surg 1: 107. doi:10.4172/2329-6925.1000107

Copyright: $\odot 2013$ França K, et al. This is an open-access article distributed under the terms of the Creative Commons Attribution License, which permits unrestricted use, distribution, and reproduction in any medium, provided the original author and source are credited. 
Citation: França K, Jennifer Ledon BS, Jessica Savas BS, Nouri K (2013) Psychological Impact of Cutaneous Congenital Vascular Lesions. J Vasc Med Surg 1: 107. doi:10.4172/2329-6925.1000107

Page 2 of 2

Results were compared with normative data for the local population or with a control group. The authors found that compared to children with PWS, children with PE had poorer self-perception, higher concentration anxiety, and more internalizing and externalizing symptoms and they were more withdrawn and had more social problems. Interestingly, the children with PWS functioned as well as or better than non-disfigured peers on measurements of psychosocial adjustment, while children with PE scored lower than non-disfigured peers on measures of selfperception and parent-rated social and attention problems [18].

A study published in the British Journal of Plastic Surgery assessed the impact of facial port wine stains on behavioral problems in children and on health related quality of life in adults applying for laser treatment. Two standard general instruments and a more specific PWS questionnaire were used. Adolescents and adults (13-31 years) received a short version of the RAND Health Insurance Questionnaire from the Medical Outcome Study (MOS-24). Children's (4-12 years) parents received the Child Behavior Checklist (CBCL). A specific PWS questionnaire was sent to both age groups. Adolescents and adults reported little effect on role and social functioning, but showed low scores for mental health, self-perceived health and vitality/health. Children's parents reported no clinically significant problem behavior. Considering the specific PWS questionnaire, adults experienced more negative psychosocial consequences of having a PWS than children [19].

Hemangiomas may have a similar psychological impact in children. A study performed with 39 children assessed the psychosocial impact of hemangiomas and their treatment on children with the disease and their families. The authors found a negative effect on the child's family, with considerable fear caused in part by adverse public commentary or attitudes. However, most parents observed that their child was too young to appreciate the condition; the family's perception was that treatment (laser, intralesional corticosteroids, oral corticosteroids, surgery, or a combination) did not change the child's emotional response to the disease and overall, the child was not deeply affected by his or her condition [20].

Despite the generally benign nature of the lesion and the prognosis for eventual involution, disfiguring facial hemangiomas in young children are frequently associated with parental reactions of grief and loss [21].

A recent review about the psychosocial impact of infantile haemangiomas on children and their parents observed that all but one of the studies investigating the psychosocial impact of hemangiomas were conducted in small groups of parents and all have flaws [22].

This brief overview of the current literature available showed some interesting points of the psychological impact caused by cutaneous vascular lesions. More studies are necessary to better clarify the psychological impact that cutaneous vascular lesions may cause. The multidisciplinary team that deals with these patients has to be prepared to understand not only the physical impact but also the psychological issues that may arise. Health professionals must be trained to identify patients with psychological distress as well as family members and be available to provide the necessary psychological help. Social support, social interaction skills and correct information and involvement are some of the possible strategies to improve patient's quality of life.

\section{References}

1. Mulliken JB, Glowacki J (1982) Hemangiomas and vascular malformations in infants and children: a classification based on endothelial characteristics. Plast Reconstr Surg 69: 412-422.

2. Finn MC, Glowacki J, Mulliken JB (1983) Congenital vascular lesions: clinical application of a new classification. J Pediatr Surg 18: 894-900.

3. Bruckner AL, Frieden IJ (2003) Hemangiomas of infancy. J Am Acad Dermatol 48: 477-493; quiz 494-496.

4. Persky MS (1986) Congenital vascular lesions of the head and neck Laryngoscope 96: 1002-1015.

5. Rasheed R, Durr-e-Sabih, Rahim MK, Uddin N (2009) Klippel-Trenaunay syndrome. J Coll Physicians Surg Pak 19: 729-731.

6. Thomas-Sohl KA, Vaslow DF, Maria BL (2004) Sturge-Weber syndrome: a review. Pediatr Neurol. 30: 303-310.

7. Wall TL (2007) Current Concepts: Laser Treatment of Adult Vascular Lesions Semin Plast Surg 21: 147-158.

8. Krishna S (2009) Disfigurement: Psychosocial Impact and Coping. 54 The Open Dermatology Journal 3: 54-57.

9. Van Moffaert M (1992) Psychodermatology: an overview. Psychother Psychosom 58: 125-136.

10. Barankin B, DeKoven J (2002) Psychosocial effect of common skin diseases. Can Fam Physician 48: 712-716.

11. Patel AM, Chou EL, Findeiss L, Kelly KM (2012) The horizon for treating cutaneous vascular lesions. Semin Cutan Med Surg 31: 98-104.

12. Gupta G, Bilsland D (2000) A prospective study of the impact of laser treatment on vascular lesions. Br J Dermatol 143: 356-359.

13. Pertschuk M, Whitaker T (1982) Social and psychological effects of craniofacia deformity and surgical reconstruction. Clin Plast Surg 9: 297-306.

14. Leonard B, Brust J, Abrahams G, Sielaff B (1991) Self-concept of children and adolescents with cleft lip and/or palate. Cleft Palate Craniofac J 28: 347-353.

15. Kendall-Grove B, Ende D, Patterson D, Johnson V (1998) Rates of dysfunction in parents of pediatric patients with burns. J Burn Care Rehabil 19: 312-316.

16. Lefebvre A, Travis F, Arndt E (1986) A psychiatric profile before and after reconstructive surgery in children with Apert's syndrome. Br J Plast Surg 39: $510-513$.

17. McDaniel DH (1990) Cutaneous vascular disorders: advances in laser treatment. Cutis 45: 339-341, 346-349, 354-360.

18. Sheerin D, MacLeod M, Kusumakar V (1995) Psychosocial adjustment in children with port-wine stains and prominent ears. J Am Acad Child Adolesc Psychiatry 34: 1637-1647.

19. Van der Horst CM, de Borgie CA, Knopper JL, Bossuyt PM (1997) Psychosocial adjustment of children and adults with port wine stains. Br J Plast Surg 50 : 463-467.

20. Williams EF 3rd, Hochman M, Rodgers BJ, Brockbank D, Shannon L, et al (2003) A psychological profile of children with hemangiomas and their families. Arch Facial Plast Surg 5: 229-334.

21. Tanner JL, Dechert MP, Frieden IJ (1998) Growing up with a facial hemangioma: parent and child coping and adaptation. Pediatrics 101: 446-452.

22. Zweegers J, van der Vleuten (2012) The psychosocial impact of an infantile haemangiomas on children and their parents. Arch Dis Child 97: 922-926. 